\title{
Unusual Cranial Metastasis from Hepatoma Presenting as Isolated Unilateral Hypoglossal Nerve Paresis
}

\author{
-Case Report-
}

\author{
Toshitaka SHIRAISHI, Hajime YANAGIDA, Kiyonori TAKADA* \\ and Yoshifumi YASUHARA** \\ Departments of Neurosurgery, ${ }^{*}$ Internal Medicine, and ${ }^{* *}$ Radiology, \\ Ehime Prefectural Imabari Hospital, Imabari, Ehime
}

\begin{abstract}
A 45-year-old male presented with a rare right hypoglossal nerve paresis due to an unusual cranial metastatic tumor from hepatoma. Despite multi-drug chemotherapy and arterial embolization, he died about 1 year later. Such metastasis should be considered as the cause of isolated unilateral hypoglossal nerve paresis.
\end{abstract}

Key words: alpha-fetoprotein, metastasis, hepatoma, hypoglossal nerve, cranial nerve paresis

\section{Introduction}

Cranial metastasis from hepatoma is rare compared to that from breast, lung, prostate, thyroid, or kidney carcinoma. A metastatic lesion causing an isolated unilateral hypoglossal nerve paresis is unusual. Here, we describe a case of an isolated hypoglossal nerve paresis as the initial symptom of cranial metastasis from hepatoma.

\section{Case Report}

This 45-year-old male was admitted to our department of neurosurgery on November 7, 1989, complaining of tongue deviation and dysarthria beginning 45 days earlier. He had developed right headache 2 months previously. Liver dysfunction had been diagnosed 3 years previously.

General physical examination was normal, including the thyroid, prostate, and testes. Neurological examination found no abnormalities apart from tongue deviation to the right on protrusion. No atrophy or fasciculation of the right lingual muscle was present. In particular, the IXth to XIth cranial nerves were not involved. Neither long-tract motor nor sensory dysfunction was present. No cervical or cranial bruits were audible. Plain head and chest $\mathrm{x}$-ray films demonstrated no abnormality. A postcontrast computed tomographic (CT) scan through the skull base with $5 \mathrm{~mm}$ sections showed an enhanced mass destroying the clivus and involving the right hypoglossal canal (Fig. 1). A bone scintigram found increased uptakes in the right fourth rib, the right scapula, and the sternum, but no clear hot area in the clivus, due to superimposition on the hot paranasal sinuses. A CT scan of the abdomen demonstrated multiple low-density areas involving the entire hepatic parenchyma. Upper gastrointestinal fiberscopy found no lesions in the esophagus,
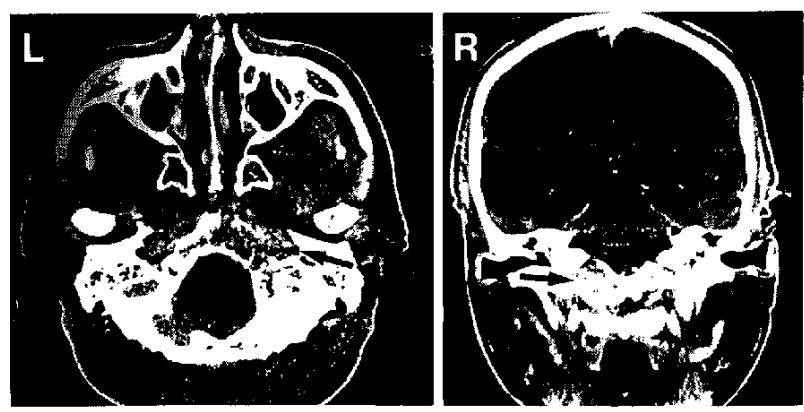

Fig. 1 Postcontrast axial (left) and coronal CT scans (right), showing an enhanced lesion (arrow) destroying the clivus adjacent to the right hypoglossal canal. 


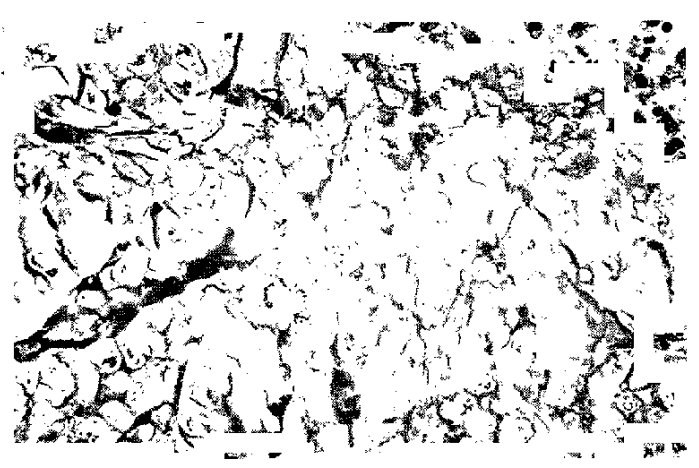

Fig. 2 Photomicrograph of liver biopsy sample, showing hepatocellular carcinoma classified as Edmondson grade III. HE stain, $\times 400$.

stomach, and duodenum.

Laboratory tests demonstrated mild liver dysfunction: hepatitis Bs (HBs) antibody, negative; HBs antigen, $\times 25,600$; hepatitis $\mathrm{Be}(\mathrm{HBe})$ antibody, negative; HBe antigen, positive (index, 4.7); alphafetoprotein, $13,958 \mathrm{ng} / \mathrm{ml}$; and carcinoembryonic antigen, $3.1 \mathrm{ng} / \mathrm{ml}$. The three major immunoglobulin (Ig) levels were normal: IgG, $1100 \mathrm{mg} / \mathrm{dl}$; IgA, $343 \mathrm{mg} / \mathrm{dl}$; and IgM, $145 \mathrm{mg} / \mathrm{dl}$. The test for Bence Jones protein in urine was negative.

Diagnosis of multiple bone metastases from hepatoma was made. Hepatic angiograms indicated hepatoma. The clinical diagnosis of hepatoma was based on the $\mathrm{CT}$ and angiographic appearance of the hepatic mass associated with very high serum alphafetoprotein levels. Another possibility was other tumors (such as gastric cancer, pancreatic cancer, or germ-cell tumor) producing high levels of alphafetoprotein. This was excluded by upper gastrointestinal fiberscopy, abdominal CT scanning, and physical examination of the testes.

Adriamycin and mitomycin-C were injected through the hepatic artery, and transcatheter hepatic arterial embolization was performed. Attempted biopsies of the tumor in the skull base through the epipharynx, and the tumor in the right scapula failed. Anticarcinogenic drugs were administered intravenously and orally. However, the serum alphafetoprotein level gradually increased. Atrophy and fasciculation of the right lingual muscle and paresis of the right soft palate developed. He was referred to another hospital for irradiation of the skull base and affected bones. The last serum alpha-fetoprotein level was $1,618,700 \mathrm{ng} / \mathrm{ml}$ on September 7 , 1990. He died of liver failure on October 3, 1990. A needle biopsy of the liver and histological examination revealed hepatocellular carcinoma of
Edmondson grade III (Fig. 2).

\section{Discussion}

Previous autopsy series show $30-70 \%$ of hepatoma patients have metastases. However, the most common metastatic sites are the lung (37-70\%) and lymph nodes $(23-45 \%))^{6,7,11,16)}$ Skeletal metastases from hepatoma are rare $(2-13 \%)$, with the spine, ribs, and long bones most frequently involved..$^{6,7,11,12,16)}$ Cranial metastases are the rarest type $(0.5-6 \%){ }^{3,9)}$ Dissemination to the bone occurs through either the pulmonary circulation or the vertebral venous plexus. ${ }^{12)}$ The latter is more probable because most reported metastases were in the vertebral bodies, ribs, and skull bones, and pulmonary metastases were absent, as in this case.

Ogasawara et al. ${ }^{\text {9) }}$ reviewed 13 cases with cranial metastasis from hepatoma. The metastatic sites were the calvarium in seven cases and the base of the skull in six. The most common initial symptoms were local swellings in calvarial metastases and multiple cranial neuropathies in skull base metastases. An isolated cranial nerve deficit, as in our case, is unusual.

Isolated unilateral hypoglossal nerve paresis has been associated with hypoglossal neurinoma, ${ }^{13)}$ radiation-induced neuropathy, ${ }^{2)}$ vascular entrapment, ${ }^{17)}$ infectious mononucleosis, ${ }^{18)}$ influenza vaccination, ${ }^{4)}$ common cold, ${ }^{1)}$ occipital condyle fracture, ${ }^{10}$ tooth extraction, ${ }^{15)}$ multiple myeloma, ${ }^{5)}$ chondroid chordoma, ${ }^{8)}$ and metastatic tumor. ${ }^{14)}$ Rubinstein ${ }^{14)}$ reported seven patients presenting with mononeuropathy of the hypoglossal nerve as the first sign of intracranial metastasis. Two patients had Hodgkin's disease, three had bronchogenic carcinoma, one had acute leukemia, and one had giant follicular lymphoma. However, cranial nerve signs have never preceded other malignancies. All these causes of isolated unilateral hypoglossal nerve paresis are extremely rare. Metastasis should therefore be considered in the differential diagnosis.

\section{References}

1) Afifi AK, Rafai ZH, Faris KB: Isolated, reversible, hypoglossal nerve palsy. Arch Neurol 41: 1218, 1984

2) Berger PS, Bataini JP: Radiation-induced cranial nerve palsy. Cancer 40: 152-155, 1977

3) Chang YC, Chen RC: Craniospinal and cerebral metastasis of primary hepatoma. A report of 7 cases. J Formosan Med Assoc 78: 594-604, 1979

4) Felix JK, Schwartz RH, Myers GJ: Isolated hypoglossal nerve paralysis following influenza vaccination. Am J Dis Child 130: 82-83, 1976 
5) Kanoh $T$, Ohno $T$, Kato $Y$, Uchino H: Hypoglossalnerve palsy in multiple myeloma. Nippon Ketsueki Gakkai Zasshi 50: 178-181, 1987 (in Japanese)

6) Kuhlman JE, Fishman EK, Leichner PK, Magid D, Order SE, Siegelman SS: Skeletal metastases from hepatoma. Frequency, distribution, and radiographic features. Radiology 160: 175-178, 1986

7) Linder GT, Crook JN, Cohn I: Primary liver carcinoma. Cancer 33: 1624-1629, 1974

8) Millingen $K$, Prentice $M$ : Isolated unilateral hypoglossal nerve palsy due to a chondroid chordoma. Clin Exp Neurol 23: 213-217, 1987

9) Ogasawara $H$, Inagawa $T$, Yamamoto $M$, Kamiya $K$, Monden S: Cranial metastasis of hepatocellular carcinoma: Case report. No Shinkei Geka 16: 14791482, 1988 (in Japanese)

10) Orbay T, Aykol S, Seckin Z, Ergun R: Late hypoglossal nerve palsy following fracture of the occipital condyle. Surg Neurol 31: 402-404, 1989

11) Patton RB, Horn RC: Primary liver carcinoma: Autopsy study of 60 cases. Cancer 17: 757-768, 1964

12) Raghavaiah NV: Hepatocellular carcinoma presenting as multiple bone metastases. Int Surg 62: 234235,1977

13) Robinson JS, Lopes J, Moody R: Intracranial hypoglossal neurilemmoma. Surg Neurol 12: 496-
498,1979

14) Rubinstein MK: Cranial mononeuropathy as the first sign of intracranial metastases. Ann Intern Med 70: 49-54, 1969

15) Stankiewicz JA, Pazevic JP: Hypoglossal nerve palsy after tooth extraction. $J$ Oral Maxillofac Surg 46: 148-149, 1988

16) Talerman A, Magyar E: Hepatocellular carcinoma presenting with pathologic fracture due to bone metastases. Cancer 32: 1477-1481, 1973

17) Ueda S, Kohyama Y, Yakase K: Peripheral hypoglossal nerve palsy caused by lateral position of the external carotid artery and an abnormally high position of bifurcation of the external and internal carotid arteries: A case report. Stroke 15: 736-739, 1984

18) Wright GDS, Lee KD: An isolated right hypoglossal nerve palsy in association with infectious mononucleosis. Postgrad Med J 56: 185-186, 1980

Address reprint requests to: T. Shiraishi, M.D., Department of Neurosurgery, Ehime Prefectural Imabari Hospital, 4-5-5 Ishii-cho, Imabari, Ehime 794, Japan. 